\title{
Reef Grief: investigating the relationship between place meanings and place change on the Great Barrier Reef, Australia
}

\author{
Nadine Marshall ${ }^{1,2}{ }^{-} \cdot$ William Neil Adger $^{3} \cdot$ Claudia Benham $^{2} \cdot$ Katrina Brown $^{3} \cdot$ Matthew I Curnock $^{1}$. \\ Georgina G Gurney ${ }^{4}$ Paul Marshall ${ }^{5}$. Petina L Pert ${ }^{1} \cdot$ Lauric Thiault $^{6,7}$
}

Received: 14 June 2018 / Accepted: 24 January 2019 / Published online: 25 February 2019

(c) The Author(s) 2019

\begin{abstract}
It is well established that ecosystems bring meaning and well-being to individuals, often articulated through attachment to place. Degradation and threats to places and ecosystems have been shown to lead to loss of well-being. Here, we suggest that the interactions between ecosystem loss and declining well-being may involve both emotional responses associated with grief, and with observable impacts on mental health. We test these ideas on so-called ecological grief by examining individual emotional response to well-documented and publicized ecological degradation: coral bleaching and mortality in the Great Barrier Reef ecosystem. The study focuses both on one off events of coral loss and the prospect of continuing decline on the self-reported well-being of residents living within the ecosystem, visitors, and those whose livelihood is dependent on the marine resource: data from face-to-face surveys of 1870 local residents, 1804 tourists, and telephone surveys of 91 fishers and 94 tourism operators. We hypothesise that the extent to which individuals experience ecological grief is dependent on the meanings or intrinsic values (such as aesthetic, scientific, or biodiversity-based values), and is moderated by their place attachment, place identity, lifestyle dependence, place-based pride, and derived well-being. Results show that around half of residents, tourists and tourist operators surveyed, and almost one quarter of fishers, report significant Reef Grief. Reef Grief is closely and positively associated with place meanings within resident and tourist populations. By contrast respondents who rated high aesthetic value of the coral ecosystem report lower levels of Reef Grief. These findings have significant implications for how individuals and populations experience ecosystem decline and loss within places that are meaningful to them. Given inevitable cumulative future impacts on ecosystems from committed climate change impacts, understanding and managing ecological grief will become increasingly important. This study seeks to lay conceptual and theoretical foundations to identify how ecological grief is manifest and related to meaningful places and the social distribution of such grief across society.
\end{abstract}

Keywords Place attachment $\cdot$ Ecological grief $\cdot$ Climate change $\cdot$ Sense of place $\cdot$ Place value $\cdot$ Commercial fishing . Cultural values $\cdot$ Ecosystem services

Handled by: Richard Clark Stedman, Cornell University.

Nadine Marshall

nadine.marshall@csiro.au

1 CSIRO Land and Water, CSIRO Oceans and Atmosphere, Townsville, Australia

2 College of Science and Engineering, James Cook University, Townsville, Australia

3 Geography, College of Life and Environmental Sciences, University of Exeter, Exeter, UK
4 ARC Centre of Excellence, James Cook University, Townsville, Australia

5 Reef Ecologic, Townsville, Australia

6 National Center for Scientific Research, PSL Université Paris, CRIOBE, USR 3278, CNRS-EPHE-UPVD, Maison des Océans, 195 rue Saint-Jacques, 75005 Paris, France

7 Laboratoire d'Excellence CORAIL, Moorea, French Polynesia 


\section{Introduction}

As we accelerate into the Anthropocene-a new era characterised by global-scale impacts of human activity on climate, biology and geochemistry (Waters et al. 2016), we are increasingly confronted with the implications of significant changes to our natural surroundings. The pervasive narrative and accumulating personal experiences of declines in ecological condition frequently give rise to strong emotional reactions in individuals, colloquially referred to as 'global mourning'. Consequently, a new science of 'loss' associated with the environment has emerged (Barnett et al. 2016). The psychological science of loss acknowledges the values that people place on the natural world and how these values are imperilled by global change, providing the basis for identifying strategies for acknowledging and managing grief as a natural human response to loss (Barnett et al. 2016). Although processes of grief and mourning are well understood in the psychological literature (for example, within the context of the loss of a loved person), these concepts are rarely applied to losses encountered in the natural world (Head and Harada 2017; Cunsolo and Ellis 2018).

Ecological grief has been proposed as the term to describe the emotional suffering associated with losses to valued species, ecosystems and landscapes (Benham 2016; Bartual 2017; Cunsolo and Ellis 2018). It can take many forms, differ across cultures, vary greatly among individuals, and even be experienced differently by the same individual each time a different loss is encountered. It can refer to experienced or anticipated losses and is expressed through mental and emotional reactions such as sadness, distress, despair, anger, fear, helplessness, hopelessness, depression, pre- and post-traumatic stress. It can also occur through disruptions to sense of place and place attachment, loss of personal or cultural identity, and ways of knowing. Leopold (1953) was among the first of many ecologists and conservationists to describe the emotional pain of experienced ecological loss, remarking that "one of the penalties of an ecological education is that one lives alone in a world of wounds" (Cunsolo and Ellis 2018, pp 275-281).

Worldwide, humans are experiencing increases in physical and mental disease that have been connected to the persistent impact of development and climate change (Berry 2009; Berry et al. 2018). Environmentally-induced population migration has been connected to desertification and global warming, as well as to changes in habitats resulting from development projects, industrial accidents, and warfare (Adams and Adger 2013; Adams et al. 2016). However, ecological grief remains an undeveloped area of research despite the unrelenting and anticipated impacts of global environmental change. This may be because ecological grief is not typically publicly or openly acknowledged, and is often absent in climate change narratives, policy and research (Adger 2016; Adger et al. 2017). Adger et al. (2017, page 371) suggests that this grief is 'disenfranchised' because there is an "implicit assumption that climate change only becomes important to society when it affects material aspects of well-being, those most easily summarized in economic costs". If climate change continues to impact upon places that people care about, then acknowledging, understanding and managing ecological grief will become critical, as will the need for conceptual and theoretical foundations that enhance our understanding of it.

While climate change is a global phenomenon, its physical impacts are experienced most acutely in the special places within which people live, work and associate significant meanings (Devine-Wright 2013; Heimann and Mallick 2016; Nicolosi and Corbett 2018). Place meaning thus highlights the "local material and symbolic contexts in which people create their lives, and through which those lives derive meaning" (Adger et al. 2017, pp 371). People develop emotional bonds with their socio-physical environment (Fresque-Baxter and Armitage 2012; Devine-Wright 2013; Masterson et al. 2017), which may in turn lead individuals to identify with places and to feel a sense of belonging. Thus, 'sense of place' and established dimensions such as place-attachment and place-based identities have become important concepts in the analysis of the cultural, personal and mental health risks associated with a changing climate (Brugger et al. 2015; Ellis and Albrecht 2017; Clarke et al. 2018; Cunsolo and Ellis 2018; Tan et al. 2018). Sense of place is referred to here as the emotional connection that people develop with a certain place that can include unique personal experiences, specific or meaningful objects (including parents, homes, jobs and pets) within the place, and the formal and informal networks that exist (Vong et al. 2015, 2016; Zhu et al. 2017). Place attachment describes the selfassessed strength of the connection, and place identity refers to the distinctive character of the place and the resulting identity that people create about themselves as a result of living within it (Marshall et al. 2012; Gurney et al. 2017; Lee et al. 2018).

Place meanings provide an opportunity to capture deeper insights into the relationships that people have with a declining natural resource more broadly than 'sense of place', or place attachment, alone (Devine-Wright et al. 2015; Nicolosi and Corbett 2018). The meanings that people attribute to place reflect the collective outlooks and behaviours of people, or culture, from which strategies to respond to environmental problems are also devised and implemented (Adger et al. 2013). The culture (i.e., traditions, customs, and way of life) that forms around a natural 
environment can be so integral to people's lives that disassociation from the natural environment can result in disorientation and disempowerment (Bonaiuto and Bonnes 1996; Fried 2000). Similarly, climate change can severely impact on the cultural relationship that people have with natural places in ways that are perceived as loss (Barnett et al. 2016). Marshall et al. (2018) proposed a list of ways in which the natural environment can be culturally important to people, that could be incorporated into environmental strategic planning, and which we adopt in this study as 'place meanings' or 'place values' (Marshall et al. 2018). Such cultural values include attachment to place, lifestyle around a place, pride in the status of a place, place identity, and well-being (associated with a place) as well as the appreciation of a place's aesthetic and biodiversity-based values. Cultural values thus incorporate both place based values (such as attachment to place, and place identity) as well as intrinsic values (such as aesthetic, scientific, or biodiversity-based values), which exist independently of place. Here, we sought to establish whether people who hold stronger place values are more likely to experience ecological grief in the event of environmental decline or loss of species.

We refer to the case of the Great Barrier Reef (GBR), a region currently experiencing significant ecological, economic and social change, and refer to the potential experience of ecological grief within the region as "Reef Grief". The GBR is the largest and most diverse coral reef ecosystem on Earth, spanning $2300 \mathrm{~km}$ along the east coast of Queensland, Australia. The GBR is one of the most inspiring landscapes within Australia (Marshall et al. 2016; Goldberg et al. 2018, Accepted 19/02/2018). It supports a community of nearly 800,000 people, and produces around $\$ 6.4$ billion per year of economic activity (Deloitte Economics 2017). The GBR is a vital contribution to the well-being of the local people, as well as for Australians more broadly (Larson et al. 2013; Stoeckl et al. 2014). Recent surveys have documented the rich and diverse relationship that local residents, Australians, tourists, commercial fishers and tourism operators have with the GBR including use, attitudes, perceptions of threats, experiences, values, aspirations, and levels of satisfaction (Gurney et al. 2017; Marshall et al. 2017). For example, $90 \%$ of local residents in the region felt that the GBR had outstanding beauty, were satisfied with their experience of it, and were proud of its World Heritage Area status. However, following a spate of severe and cumulative regionalscale impacts, from tropical cyclones, mass coral bleaching (in both 2016 and 2017), and an ongoing outbreak of coral-eating crown of thorns starfish, recent ecological monitoring suggests that the proportion of live coral coverage across all regions of the World Heritage Area have undergone a steep decline, to an extent not observed in the historical record (AIMS Long-Term Monitoring Program 2018, available at https://www.aims.gov.au/reef-monit oring/gbr-condition-summary-2017-2018).

The extent to which local communities (including commercial fishers and tourism operators) as well as domestic and international tourists are experiencing Reef Grief as a result of coral bleaching are effectively unknown, although research in the GBR context suggests that communities experiencing localised degradation of the marine environment as a result of industrial development similarly contextualise this experience as a grieving process (Benham 2016). This effect is enhanced among residents who rated the environment as "pristine" prior to the start of development. Our concern lies mostly with the ways in which people might cope and adapt to their rapidly changing and beloved resource. Specifically, our aims were to assess, (i) the current level of Reef Grief amongst key stakeholder groups within the GBR region, and (ii) to explore how a range of seven different place meanings are related to Reef Grief.

\section{Methods}

\section{Survey design}

The survey questions and data used for this study were obtained from the Social and Economic Long Term Monitoring Program (SELTMP) for the Great Barrier Reef (Marshall et al. 2016). The data are publically available at https ://research.csiro.au/seltmp/. A survey template was used so as to ask similar questions to all stakeholder groups where possible (see https://research.csiro.au/seltmp/).

A single survey statement was used to assess the extent that Reef Grief might be occurring within all stakeholder groups of the GBR: "Thinking about coral bleaching makes me feel depressed". Survey participants were asked to agree or disagree with this statement on a ten-point scale where a rating of 1 represented "very strongly disagree" and 10 represented, "very strongly agree".

Drawing on Marshall et al. (2018)'s framework of human-environment cultural values, we examined different meanings or values that people held for the GBR (Table 1). Some questions about living within the GBR region were not for tourists. Instead, we asked a similar question about the importance of visiting the GBR (Table 1).

Additional questions were also used to understand how the GBR was used, and to describe the demographics of each group. We also asked whether people recognised bleaching as one of the top three threats to the GBR (given that recognition of bleaching as a threat would influence whether people were depressed about it). 
Table 1 A selection of cultural values associated with the Great Barrier Reef (GBR) region and tested in this study using the statements listed from the Social and Economic Long Term Monitoring Program for the GBR (Marshall et al. 2016)

\begin{tabular}{|c|c|}
\hline Cultural values & Description \\
\hline Identity & $\begin{array}{l}\text { The feeling of belonging to a place or social group with its own distinct culture and common } \\
\text { social values and beliefs (Adger et al. 2011; Marshall et al. 2012) } \\
\text { Survey statement "The GBR is part of my identity" }\end{array}$ \\
\hline Pride in resource status ("Pride") & $\begin{array}{l}\text { The sense of attachment toward a place or its status, such as World Heritage Area designation; } \\
\text { this can be linked to a signal of high social status (Marshall et al. 2016) } \\
\text { Survey statement "I feel proud that the GBR is a World Heritage Area" }\end{array}$ \\
\hline Attachment to place ("Place") & $\begin{array}{l}\text { The emotional and physical bond between person and place, which is influenced by experiences, } \\
\text { emotions, memories, and interpretations; it often provides a reason for people to live in a spe- } \\
\text { cific area (Devine-Wright 2010; Adger et al. 2013; Gurney et al. 2017) } \\
\text { Survey statement "I live here because of the GBR" (residents only) } \\
\text { "I love that I have visited the GBR" (tourists only) }\end{array}$ \\
\hline Aesthetic appreciation (“Aesthetic”) & $\begin{array}{l}\text { Describes the aesthetic value that an individual attributes to aspects of an ecosystem; aesthetic } \\
\text { responses are linked to both the characteristics of an environment and culturally or personally } \\
\text { derived preferences (Millenium Ecosystem Assessment 2005; Pike et al. 2011; Klain et al. } \\
\text { 2014) } \\
\text { Survey statement "The aesthetic beauty of the GBR is outstanding" (Lopez-Hoffman et al. 2010; } \\
\text { van Riper et al. 2012) }\end{array}$ \\
\hline Appreciation of biodiversity ("Biodiversity") & $\begin{array}{l}\text { Describes how people are emotionally inspired by biodiversity and other measures of ecosystem } \\
\text { integrity at a particular place (Marshall et al. 2016) } \\
\text { Survey statement "I value the GBR because it supports a variety of life, such as fish and corals" }\end{array}$ \\
\hline Lifestyle & $\begin{array}{l}\text { The expression of "visible" culture that has evolved around a natural resource or ecosystem; } \\
\text { describes the extent to which the lives of people revolve around a natural resource and how peo- } \\
\text { ple interact with it for recreation (Millenium Ecosystem Assessment 2005; Marshall et al. 2016) } \\
\text { Survey statement "I value the GBR because it supports a desirable and active way of life" (Hawke } \\
\text { 2010; Negi 2010) }\end{array}$ \\
\hline
\end{tabular}

Participants were asked to rate how strongly they agreed with each statement on a scale of $1-10$, where $1=$ strongly disagreed and $10=$ strongly agreed

\section{Survey administration}

A mixed-methods approach was used to collect survey data. Local residents and tourists were surveyed using face-toface methods across 14 main population centres along the Great Barrier Reef. We employed and trained 45 casual staff (mostly students) and deployed them to public places such as parks, shopping centres, market places, airports, marinas, sporting areas, festivals, information centres, museums, jetties, caravan parks, lookouts, and other public spaces. We used a mix of "convenience sampling" and "quota sampling" (Bryman 2012) in which we were able to capture a sample of people representative of the Queensland population across the demographic categories of age, gender and income (www.abs.gov.au). A limitation of our sampling was a bias towards English speaking people. Interviewers were equipped with an Apple mini-iPad loaded with an iSurvey application for both the residents' survey and the tourist survey. As data were instantly uploaded, we were able to manage interviewers to ensure that gender and age were as representative as possible of the local community. A total of 1870 local residents and 1804 tourists were surveyed, obtaining a response rate of over 50\%. Residents were defined as people who live within the Reef catchment (east of Great Dividing
Range, from Bundaberg to Cape York), while tourists lived anywhere outside of that area, either elsewhere in Australia or internationally (Marshall et al. 2016).

Marine tourism operators and commercial fishers were interviewed by telephone. We built our own contacts databases using publicly-available data, personal contacts and unpublished data. In 2013, we identified 213 tourism operators and 611 commercial fishers in possession of at least one license. A media release resulted in 44 media stories across the catchment and a targeted mail-out introducing tourism operators and fishers to the project. These strategies may have contributed to a response rate of $58 \%$ across both groups, where 94 marine tourism operators and $91 \mathrm{com}$ mercial fishers were surveyed.

\section{Data analysis}

We undertook a regression analysis to assess the relationship between Reef Grief and the seven GBR place meanings. We first checked for collinearity among our covariates (Table 1) using pairwise correlations and variance inflation factor estimates. This led to the exclusion of the "wellbeing" cultural value as it was strongly correlated with "identity" $(r=0.7)$ and was the most collinear with other covariates. 
(Importantly, the covariates that exhibited the largest effect sizes in our models were not strongly collinear with other candidate covariates.) We then assessed the relative influence of each selected covariate on Reef Grief by fitting linear models for each user group. Exploratory graphical analyses of residuals were used to confirm that assumptions of homogeneity of variance and normality were met for each model. The coefficient of determination $\left(R^{2}\right)$ of the four fitted models indicated that the covariates explained $21 \%$ (tourists), $22.7 \%$ (residents), $30.1 \%$ (tourism operators), and $19.9 \%$ (commercial fishers) of the variation in the level of Reef Grief. All analyses were performed using the R statistical software.

\section{A description of the sample population}

A description of the participants that agreed to partake in the study is presented in Table 2 .

\section{Results}

\section{Level of Reef Grief within the GBR region (residents, fishers, tourism operators, tourists)}

Responses to the survey question, "thinking about coral bleaching makes me feel depressed", elicited a range of responses, however, negative responses were relatively minor, particularly for tourists and residents (Fig. 1). Residents reported a mean level of Reef Grief of 7.14 on a scale of 1-10 (SD 2.8). Tourists reported a mean Reef Grief of 6.9 (SD 2.7), tourism operators reported a mean of 6.3 (SD 3), while fishers reported lowest levels of Reef Grief, if at all, with a mean of 4.66 (SE 0.328). Some $53.5 \%$ of residents, $48.4 \%$ of tourists, $42.2 \%$ of tourism operators but only $22.9 \%$ of fishers reported significant Reef Grief (scoring 8, 9, or 10 on a ten point scale; Fig. 1).

\section{The relationship between Reef Grief and place values}

We found commonalities and differences among the four stakeholder groups in regards to the relationship between Reef Grief and the seven place meanings/values (Fig. 2).

Table 2 A description of the survey population

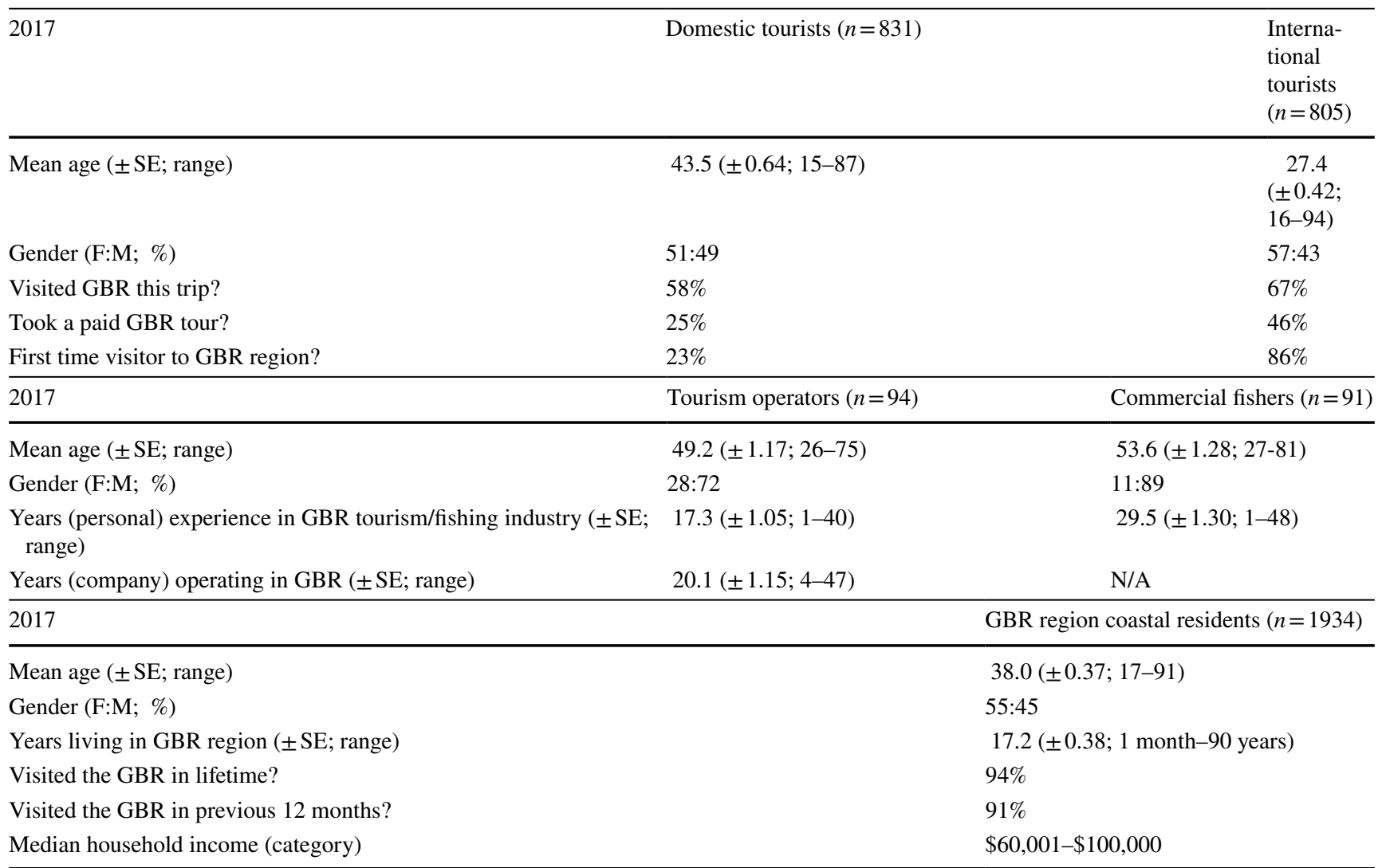



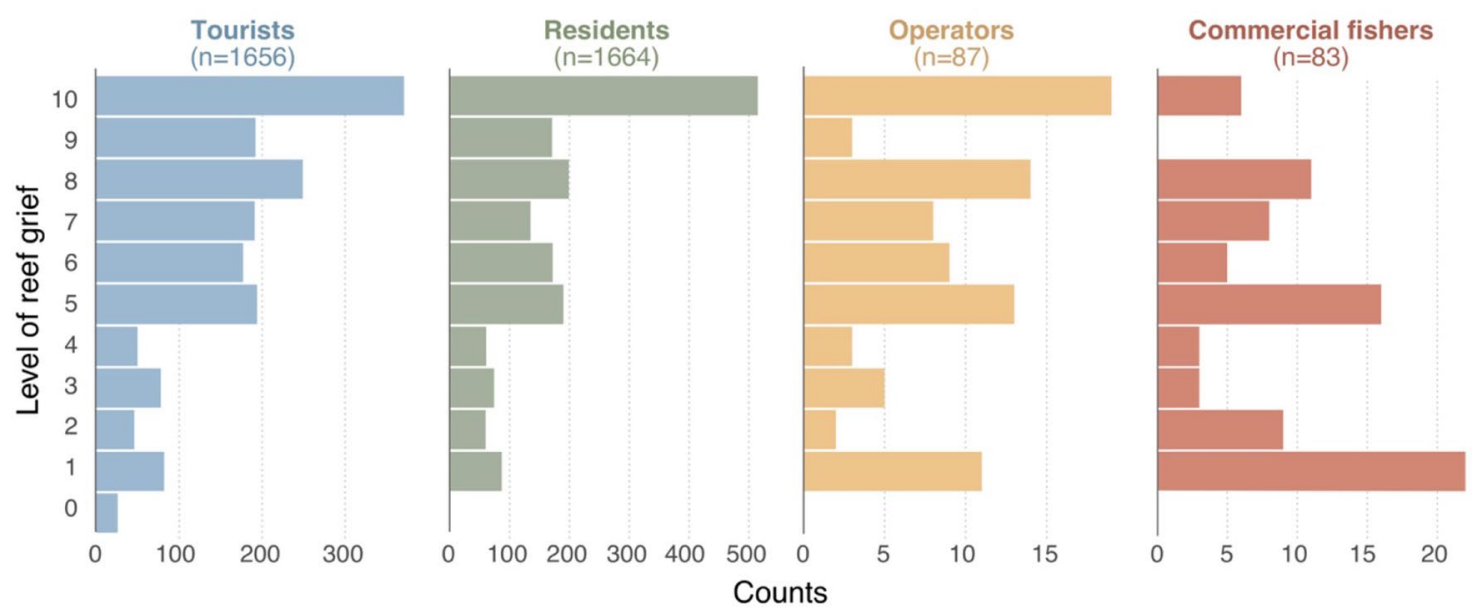

Fig. 1 Distribution of responses from each stakeholder group to the survey question, "Thinking about coral bleaching makes me feel depressed"
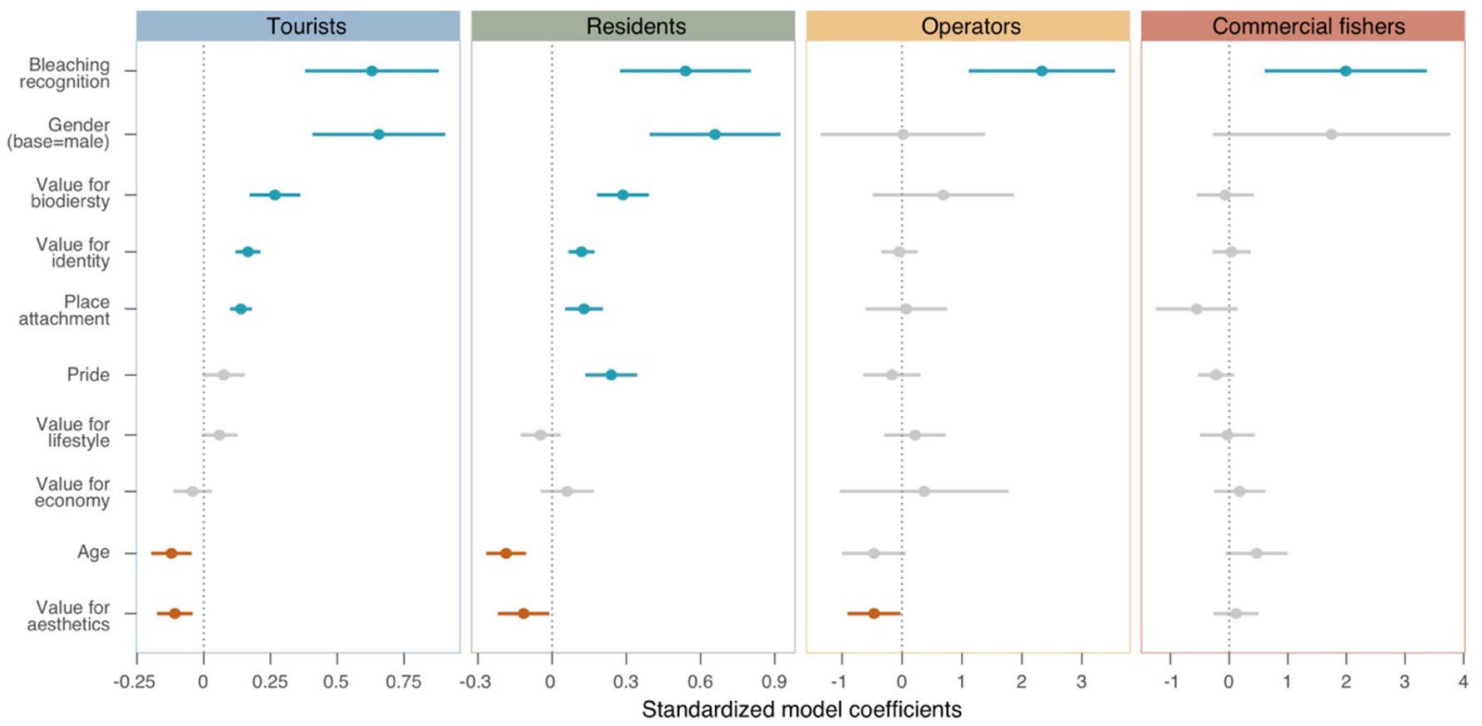

Fig. 2 Relationship between Reef Grief and seven GBR place meanings, controlling age, gender and recognition of bleaching as a threat to the GBR. Linear regression coefficients (dots) and 95\% confidence intervals indicate the statistical significance of the relationship,

Three place meanings/values, place identity, biodiversity and place attachment, were significantly positively related to Reef Grief for residents and tourists but showed no relationship for the tourism operators and fishers. Pride in the GBR was also positively related to Reef Grief for residents and tourists, but was only significant for the former stakeholder group. Residents and tourist, together with tourism operators, showed a negative association between Reef Grief and aesthetic appreciation. The seven place meanings/values were not significantly related to Reef Grief for tourism operators and within commercial fishers, with the only significant relationship with Reef Grief being aesthetic whereby intersection of the confidence interval with zero indicates lack of significance. That is, blue lines indicate a significantly positive relationship, red indicates a significantly negative relationship and grey indicates a non-significant relationship

appreciation for tourism operators; the relationship was negative (that is, the more that tourism operators appreciated the aesthetic qualities of the GBR, the less likely they were to report Reef Grief).

Across all four stakeholder groups age was a negative related to Reef Grief (where older people were less likely to report Reef Grief within residents and tourists). Female residents and tourists were more likely than males to report Reef Grief, but the effect of gender was not significant for the other two stakeholder groups. Finally, as expected, recognition of bleaching in the top three threats to the GBR was positively related to Reef Grief. 


\section{Discussion}

Ecosystems bring meaning and well-being to individuals (Diaz et al. 2011). Here, our results suggest that this relationship may well be mediated through the concept of place attachment and place meaning. Reef Grief, an emotional response to the well-documented and publicized degradation of the Great Barrier Reef (GBR) through coral bleaching and mortality, is reportedly experienced by a significant proportion of local residents as well as national and international tourists. With around half of all residents, tourists and tourism operators, and around a quarter of fishers scoring their grief as an eight, nine or ten on a ten point survey-scale, it appears that people have already entered a period of grieving and mourning for the iconic landscape even though as much as $50 \%$ of the GBR is reportedly undamaged. The extent to which individuals experience ecological grief appears to be dependent on the meanings or intrinsic values (aesthetic, scientific, or biodiversity-based values), and is moderated by their place attachment, place identity, lifestyle dependence, and place-based pride. Importantly, respondents who rated high aesthetic value of the coral ecosystem reported lower levels of Reef Grief. Ecological grief appears to be closely tied with the connection that people have with a natural resource. Respondents who rated high aesthetic value of the coral ecosystem in this study reported lower levels of Reef Grief. Presumably, this is because people who feel that the aesthetic values are still outstanding have recently visited a section of the reef in exceptional and undamaged condition, and associate joy rather than grief with the experience. Tourists, for example that directly experience the beauty of the GBR, tend to be taken only to those such sites. Younger people and females were also more likely to report Reef Grief, a pattern that follows established research on the links between gender, age and pro-environmental values (Gifford 2014). Tourism operators and commercial fishers did not report strong Reef Grief relative to residents and tourists, nor did their grief correlate with place associations as strongly as it did in residents and tourists. Instead, these industry members tended to report higher levels of Reef Grief only if worried about the negative impacts of climate change. These results suggest that these industry members may either be in denial of climate change and its impacts on the GBR, or have accepted climate change and its impacts, and have, rather pragmatically, decided to adapt. Many of these operators do not personally interact with coral reefs and may be unaware of the ecological health of their own sites, or operate at sites that have been unaffected by recent coral bleaching events. Resource-dependent people who retain close living and working relationships with the natural world, such as commercial fishers and tourism operators, foster a strong self-identity, or occupational identity, around the natural resource, including its physical features, uses and knowledge of it (Marshall et al. 2013; Ellis and Albrecht 2017; Cunsolo and Ellis 2018). Consequently, climate change can disrupt a healthy self-identity via its physical impacts upon ecosystems that are special (Adger et al. 2013; Cunsolo and Ellis 2018). For example, Cunsolo and Ellis 2018 document how threats and disruptions to sense of place from a changing climate can impact the mental and emotional health of Inuitin Arctic Canadians. Hence, acknowledging that place change is occurring within coastal communities and resource dependent industries such as commercial fishing and marine based tourism would thus also require these resource users to accept impending changes in self-identity, an extremely difficult process to undertake (Marshall et al. 2007; Gifford 2014).

These findings, albeit it with a survey sample that is known to be representative for age, gender and income only, and only using a single survey question, have significant implications for how individuals and populations experience ecosystem decline and loss within places that are meaningful to them. Future research has clearly many directions that could be taken to better understand the depth and extent of the phenomenon of ecological grief. Nonetheless, our findings contribute to a growing research momentum where, for example, Benham (2016) documents how residents in Gladstone, a port city in the southern Great Barrier Reef, reported feelings of grief in response to the impacts of rapid industrialisation on the port environment, including the loss of important fishing and recreational areas. This was enhanced by a sense of loss of the established social structure and identity as a coastal place. Ellis and Albrecht (2017) describe how disruptions to sense of place and place identity as a result of impacts from climate change in the Western Australian Wheat-belt are negatively affecting family farmers' mental wellbeing (Ellis and Albrecht 2017). Rigby et al. (2011) in their study of prolonged drought on the social and emotional well-being of Aboriginal communities in rural New South Wales, report the response of communities as, "If the land's sick, we're sick".

Place attachment and its meanings are thus likely to be important indicators of peoples' responses to the impacts of climate change upon culturally important natural resources. Subsequently, Willox et al. (2013) have called for contextspecific climate-health planning and adaptation programs, for an understanding of place-attachment as a vital indicator of health and well-being, and for climate change to be framed as an important determinant of health. However, within the context of natural resource management, we suggest that natural resource managers should consider the cultural impacts of climate change, particularly Reef Grief, and prioritise management initiatives accordingly (Adger et al. 2013). For example, GBR managers may wish to consider the stewardship potential associated with Reef Grief, where 
it might be possible to inspire people to better protect the GBR (through reporting non-compliance for a local example), through using communication strategies that emphasise the importance of protecting biodiversity, something that local residents from this study care about. Global attachment and subsequent mourning for iconic landscapes such as the GBR could also be harnessed internationally to arrest climate change (Gurney et al. 2017). Reef managers could provide timely and up-to-date information to the public, and engage the public in conservation issues around the loss of special places such as the Great Barrier Reef (Johnson and Marshall 2007). To engage with loss and grieve as a community is to find strength and maturity (Prigerson et al. 2009). Barnett et al. (2016) suggest that, whilst unsettling, embracing the possibility of loss may be the best means of offsetting its harm. Similarly, co-produced and situated research with communities can give communities ownership of the knowledge of loss and help them to come to terms with it. Such engagement has the potential to stimulate collective responsibility, creativity, and new skills. It can also change expectations of the future in ways that convert perceived losses to something less troubling (Barnett et al. 2016).

Open Access This article is distributed under the terms of the Creative Commons Attribution 4.0 International License (http://creativeco mmons.org/licenses/by/4.0/), which permits unrestricted use, distribution, and reproduction in any medium, provided you give appropriate credit to the original author(s) and the source, provide a link to the Creative Commons license, and indicate if changes were made.

\section{References}

Adams H, Adger WN (2013) The contribution of ecosystem services to place utility as a determinant of migration decision-making. Environ Res Lett 8:015006

Adams H, Adger WN, Ahmad S, Ahmed A, Begum D, Lazar AN, Matthews Z, Rahman MM, Streatfield PK (2016) Spatial and temporal dynamics of multidimensional well-being, livelihoods and ecosystem services in coastal Bangladesh. Sci Data 3:160094

Adger WN (2016) Place, well-being, and fairness shape priorities for adaptation to climate change. Glob Environ Change Hum Policy Dimens 38:A1-A3

Adger WN, Barnett J, Chapin FS, Ellemor H (2011) This must be the place: underrepresentation of identity and meaning in climate change decision-making. Glob Environ Polit 11:1-25

Adger WN, Barnett J, Brown K, Marshall N, O’Brien K (2013) Cultural dimensions of climate change impacts and adaptation. Nat Clim Change 3:112-117

Adger WN, Butler C, Walker-Springett K (2017) Moral reasoning in adaptation to climate change. Environ Polit 26:371-390

Barnett J, Tschakert P, Head L, Adger WN (2016) A science of loss. Nat Clim Change 6:976-978

Bartual MM (2017) Modifications on the concept of wilderness in the anthropocene. In: Glocal: Codificar, Mediar, Transformar, Vivir, pp 440-447

Benham C (2016) Change, opportunity and grief: understanding the complex social-ecological impacts of liquefied natural gas development in the Australian coastal zone. Energy Res Social Sci 14:61-70

Berry H (2009) Pearl in the oyster: climate change as a mental health opportunity. Australas Psychiatry 17:453-456

Berry HL, Waite TD, Dear KBG, Capon AG, Murray V (2018) The case for systems thinking about climate change and mental health. Nat Clim Change 8:282-290

Bonaiuto M, Bonnes M (1996) Multiplace analysis of the urban environment - a comparison between a large and a small Italian city. Environ Behav 28:699-747

Brugger A, Dessai S, Devine-Wright P, Morton TA, Pidgeon NF (2015) Psychological responses to the proximity of climate change. Nat Clim Change 5:1031-1037

Bryman A (2012) Social research methods. Oxford University Press, Oxford

Clarke D, Murphy C, Lorenzoni I (2018) Place attachment, disruption and transformative adaptation. J Environ Psychol 55:81-89

Cunsolo A, Ellis NR (2018) Ecological grief as a mental health response to climate change-related loss. Nat Clim Change $8: 275-281$

Deloitte Economics (2017) At what price? The economic, social and icon value of the Great Barrier Reef. Report to the Great Barrier Reef Marine Park Authority. Townsville, Australia

Devine-Wright P (2010) Place attachment and the social acceptance of renewable energy technologies. Psychol Appro Sustain 337-359

Devine-Wright P (2013) Think global, act local? The relevance of place attachments and place identities in a climate changed world. Glob Environ Change Hum Policy Dimens 23:61-69

Devine-Wright P, Price J, Leviston Z (2015) My country or my planet? Exploring the influence of multiple place attachments and ideological beliefs upon climate change attitudes and opinions. Glob Environ Change Hum Policy Dimens 30:68-79

Diaz S, Quetier F, Caceres DM, Trainor SF, Perez-Harguindeguy N, Bret-Harte MS, Finegan B, Pena-Claros M, Poorter L (2011) Linking functional diversity and social actor strategies in a framework for interdisciplinary analysis of nature's benefits to society. Proc Natl Acad Sci USA 108:895-902

Ellis NR, Albrecht GA (2017) Climate change threats to family farmers' sense of place and mental wellbeing: a case study from the Western Australian Wheatbelt. Soc Sci Med 175:161-168

Fresque-Baxter JA, Armitage D (2012) Place identity and climate change adaptation: a synthesis and framework for understanding. Wiley Interdiscip Rev Clim Change 3:251-266

Fried M (2000) Continuities and discontinuities of place. J Environ Psychol 20:193-205

Gifford R (2014) Environmental psychology matters. Annu Rev Psychol 65(65):541-579

Goldberg AG, Marshall N, Birtles A, Case P, Curnock M, Gurney GG (2018) On the relationship between attitudes and environmental behaviours of key Great Barrier Reef user groups. Ecol Soc (in press, Accepted 19/02/2018)

Gurney GG, Blythe J, Adams H, Adger WN, Curnock M, Faulkner L, James T, Marshall NA (2017) Redefining community based on place attachment in a connected world. Proc Natl Acad Sci USA 114:10077-10082

Hawke SK (2010) Belonging: the contribution of heritage to sense of place. Heritage Herit Sustain Dev 1 and 2:1331-1339

Head L, Harada T (2017) Keeping the heart a long way from the brain: the emotional labour of climate scientists. Emotion Space and Society 24:34-41

Heimann T, Mallick B (2016) Understanding climate adaptation cultures in global context: proposal for an explanatory framework. Climate 4:59

Johnson JE, Marshall PA (2007) Climate change and the Great Barrier Reef. A vulnerability assessment. Great Barrier Reef Marine Park Authority, Townsville, Australia 
Klain SC, Satterfield TA, Chan KMA (2014) What matters and why? Ecosystem services and their bundled qualities. Ecol Econom 107:310-320

Larson S, De Freitas DM, Hicks CC (2013) Sense of place as a determinant of people's attitudes towards the environment: implications for natural resources management and planning in the Great Barrier Reef, Australia. J Environ Manage 117:226-234

Lee JH, Matarrita-Cascante D, Xu Y, Schuett M (2018) Examining the conflicting relationship between US national parks and host communities: understanding a community's diverging perspectives. Sustainability 10:3667

Leopold A (1953) Round river: from the journals of Aldo Leopold. Oxford University Press, New York

Lopez-Hoffman L, Varady RG, Flessa KW, Balvanera P (2010) Ecosystem services across borders: a framework for transboundary conservation policy. Front Ecol Environ 8:84-91

Marshall NA, Fenton DM, Marshall PA, Suffon SG (2007) How resource dependency can influence social resilience within a primary resource industry. Rural Sociol 72:359-390

Marshall NA, Park SE, Adger WN, Brown K, Howden SM (2012) Transformational capacity and the influence of place and identity. Environ Res Lett 7:34022

Marshall N, Tobin R, Marshall P, Gooch M, Hobday A (2013) Social vulnerability of marine resource users to extreme weather events. Ecosystems 16:797-809

Marshall NA, Bohensky E, Curnock M, Goldberg J, Gooch M, Nicotra B, Pert P, Scherl LM, Stone-Jovicich S, Tobin RC (2016) Advances in monitoring the human dimension of natural resource systems: an example from the Great Barrier Reef. Environ Res Lett 11:114020

Marshall NA, Curnock MI, Goldberg J, Gooch M, Marshall PA, Pert PL, Tobin RC (2017) The dependency of people on the Great Barrier Reef, Australia. Coast Manag 45:505-518

Marshall NA, Barnes M, Birtles A, Brown K, Cinner JE, Curnock M, Eakin H, Goldberg AG, Gooch M, Kittinger JN, Marshall P, Manuel-Navarrete D, Pelling M, Pert P, Smit B, Tobin A (2018) Measuring what matters in the Great Barrier Reef. Front Ecol Environ 16:271-277

Masterson VA, Stedman RC, Enqvist J, Tengo M, Giusti M, Wahl D, Svedin U (2017) The contribution of sense of place to socialecological systems research: a review and research agenda. Ecol Soc 22:49

Millenium Ecosystem Assessment (2005) Ecosystems and human wellbeing: current state and trends, vol 1. Island Press, United States of America

Negi CS (2010) Traditional culture and biodiversity conservation: examples from Uttarakhand, Central Himalaya. Mt Res Dev 30:259-265

Nicolosi E, Corbett JB (2018) Engagement with climate change and the environment: a review of the role of relationships to place. Local Environ 23:77-99
Pike K, Johnson D, Fletcher S, Wright P (2011) Seeking spirituality: respecting the social value of coastal recreational resources in England and Wales. J Coast Res 2011(61):194-204

Prigerson HG, Horowitz MJ, Jacobs SC, Parkes CM, Aslan M, Goodkin K, Raphael B, Marwit SJ, Wortman C, Neimeyer RA, Bonanno GA, Block SD, Kissane D, Boelen P, Maercker A, Litz BT, Johnson JG, First MB, Maciejewski PK (2009) Prolonged grief disorder: psychometric validation of criteria proposed for DSM-V and ICD-11. PLoS Med 6:e1000121

Rigby CW, Rosen A, Berry HL, Hart CR (2011) If the land's sick, we're sick: The impact of prolonged drought on the social and emotional well-being of Aboriginal communities in rural New South Wales. Aust J Rural Health 19:249-254

Stoeckl N, Farr M, Larson S, Adams VM, Kubiszewski I, Esparon M, Costanza R (2014) A new approach to the problem of overlapping values: a case study in Australia's Great Barrier Reef. Ecosyst Serv 10:61-78

Tan SK, Tan SH, Kok YS, Choon SW (2018) Sense of place and sustainability of intangible cultural heritage-the case of George Town and Melaka. Tour Manag 67:376-387

van Riper CJ, Kyle GT, Sutton SG, Barnes M, Sherrouse BC (2012) Mapping outdoor recreationists' perceived social values for ecosystem services at Hinchinbrook Island National Park, Australia. Appl Geogr 35:164-173

Vong LTN, Lai K, Li YP (2015) Influence of casino impact perception on sense of place: a study on Casino-Liberalized Macao, China. Asia Pacific J Tour Res 20:920-941

Vong TN, Lai K, Li YP (2016) Sense of place: affective link missing between casino impact perception and support for casino development? Asia Pacific J Tour Res 21:S76-S100

Waters CN, Zalasiewicz J, Summerhayes C, Barnosky AD, Poirier C, Galuszka A, Cearreta A, Edgeworth M, Ellis EC, Ellis M, Jeandel C, Leinfelder R, McNeill JR, Richter DD, Steffen W, Syvitski J, Vidas D, Wagreich M, Williams M, An ZS, Grinevald J, Odada E, Oreskes N, Wolfe AP (2016) The Anthropocene is functionally and stratigraphically distinct from the Holocene. Science 351:137-+

Willox AC, Harper SL, Ford JD, Edge VL, Landman K, Houle K, Blake S, Wolfrey C (2013) Climate change and mental health: an exploratory case study from Rigolet, Nunatsiavut, Canada. Clim Change 121:255-270

Zhu H, Liu JM, Wei ZC, Li WH, Wang L (2017) Residents' attitudes towards sustainable tourism development in a historical-cultural village: influence of perceived impacts, sense of place and tourism development potential. Sustainability 9:61

Publisher's Note Springer Nature remains neutral with regard to jurisdictional claims in published maps and institutional affiliations. 